\title{
REDESIGNING MEDICAL STUDENTS' TRAINING THROUGH VIRTUAL CLINICAL SIMULATION
}

\author{
Segura-Azuara NA ${ }^{1 *}$ and Lopez $\mathrm{M}^{1,2}$ \\ ${ }^{I}$ Tecnologico de Monterrey, Escuela de Medicina y Ciencias de la Salud, Mexico \\ ${ }^{2}$ Writing Lab, Institute for the Future of Education, Tecnologico de Monterrey, \\ Monterrey, Mexico
}

\begin{abstract}
Clinical simulation is an engaging teaching strategy that has been used to develop disciplinary and soft skills in medical students through structured educational activities with assessment and feedback. COVID-19 has forced medical schools into redesigning many curricular activities, including these clinical simulations, which leveraged virtual technologies to continue the training amid the pandemic. The objective of this study was to assess the adaptation of clinical simulation to a virtual-based format to continue medical students' training. The sample of participants in this study was 34-thirdyear medical students. Simulation sessions were held through a synchronous videoconference platform where students used a monitor for vital signs, an actor simulated a patient, and the corresponding lab results and imaging studies were available upon students' request. Students provided care for the patient by teams; they interviewed and asked for physical exam findings from an actor representing a nurse. The simulation adapted to the team's performance, students were provided with the test results as they requested, and the patient's vital signs responded to the team's prescriptions. Following the simulation, they received feedback using the debriefing with a good-judgment framework which supports a reflection regarding their mental processes leading to decision-making. Adapting educational strategies using technology in remote teaching is essential for medical schools to continue their training. This curricular adaptation exemplifies a proficient way to carry out virtual simulation activities amid the pandemic, easily adapted to other disciplines and educational levels.
\end{abstract}

Keywords: higher education, educational innovation, professional education, pandemic adaptations, COVID-19, virtual simulation

\section{Introduction}

Medical schools worldwide are constantly trying to innovate in educational strategies to guarantee students' competencies in their training to become physicians. (Regehr, 2004). These competencies are comprised of both disciplinary and soft skills developed in different formats. As the students progress in their training, they advance from more theoretical approaches to more hands-on activity (Brouwers et al., 2019). The last part of their training is focused on applying their knowledge, skills, and attitudes to the complex clinical context where they interact with patients and their families. These interactions rely on collaboration, communication, and professionalism (Brouwers et al., 2019; Khan et al., 2013; Laidlaw et al., 2012), skills that require frequent and informed practice to achieve mastery.

Face-to-face interaction is crucial in health sciences. Here, simulation can provide an engaging learning experience that empowers students in their training, focusing on their achievements to 
strengthen them and their flaws. Some schools have curricular activities for students to develop critical clinical competencies using simulation, mainly by face-to-face interaction, which could happen during the pandemic.

Medical education is an evidence-based practice that evolves according to scientific advances and community health needs (Buja, 2019). One of the practices that widened acceptance is incorporating simulation and skill-lab practices as part of their curriculum. These programs provide a structured learning environment for students to practice various procedures, interviews with actors representing patients, mannequins, and virtual monitors, according to the teaching-learning objectives of their courses.

Simulation in medical education, defined as the recreation of healthcare situations, can be effectively used to learn basic sciences and clinical interactions with patients (Segura-Azuara et al., 2018). The primary purposes serving simulation are: education, research, assessment, and healthcare system integration, all of which aim towards higher patient safety (So et al., n.d.). By including different degrees of realism and complexity of the cases, the practices are pitched to the appropriate level of trainees. The use of sophisticated equipment can add to the realism, as can the participation of simulated healthcare personnel or patients. For example, role-play can provide a precise stimulus for students to engage by interacting with a person in which more complex scenarios are presented (Culpa-Bondal \& Dean, 2018; Lane et al., 2001; Turner et al., 2010).

But practicing without assessing if the acquired skills are accurate is dangerous; thus, the importance of providing timely feedback in the teaching-learning process. Effective techniques that provide the highest metacognition level are to be implemented (Segura-Azuara et al., 2018). Debriefing with good judgement is a well-known feedback tool that enhances the learners' experience and stimulates selfawareness to boost individual and group performance (Maestre \& Rudolph, 2015). Metacognition development allows all stakeholders to understand where they stand and why, essential for learning with clear knowledge of the motives for their actions and decision-making processes (Maestre \& Rudolph, 2015; Olivares Olivares \& Valdez-García, 2017). Trainees acquire significant experiences that they integrate into their professional practice. The pandemic yielded new challenges for these strategies that foster practice, as they relied on face-to-face interactions within a physical setting in the university. However, the affordance of losing these learning opportunities is not be waived during the pandemic.

Before COVID-19, some authors had warned about an ongoing digital transformation in healthcare (Friedman et al., 2016). In this profound change, universities have struggled to introduce technological tools to keep up with this transformation, notwithstanding the difficulties of faculty resistance and lack of training on these technologies.

COVID-19 pandemic brought an abrupt worldwide disruption for medical education. Some authors stated that this change would have taken decades to occur, but the current situation pushed an extreme makeover in all areas of healthcare (Chick et al., 2020; Joseph et al., 2020; Tabatabai, 2020; Torres et al., 2020). Suddenly, medical students and teachers had to change their teaching-learning methods to face the drastic changes related to personal protection while continuing their medical training. Several strategies were developed for clinical training, including virtual simulation-based scenarios, which offer a fresh start for different levels in the medicine program (Ahmed et al., 2020; Tabatabai, 2020). 
Geographically distant learners require a teaching tool that embraces teamwork, critical thinking, and communication skills, all of which are important for the healthcare professional in training.

The pandemic significantly impacted clinical education, from daily class planning to learning assessment practices (Tabatabai, 2020). As COVID-19 cases grew exponentially, teaching hospitals and schools closed or reduced their face-to-face interactions for some time, according to local authority policies (Valdez-García et al., 2020; Wang \& Shi, 2020). Most university programs switched rapidly to online classes, with high stakes for both training and patient assistance. Slowly, students were admitted back to the classrooms and predominantly returned to observer-related clinical activities (Ahmed et al., 2020). Different approaches to implementing efficient strategies for competencies development in students were started. Some introduced new methods; others adapted their own as one of the key elements in clinical training, simulations needed to evolve into a format in which the benefits were obtained in remote teaching-learning activities. Several medical schools made adaptations that included simulation (Patel et al., 2020).

The reported virtual clinical simulation experience consisted of 2 simulation-based cases related to the endocrine pathophysiology course, adapted to the students' training and remote teaching strategies. A graduate student played a standardized patient with diabetic ketoacidosis and in the first case and subacute thyroiditis in the second one. We had a script for the actor representing a patient to follow. He should interact with the students as if in person. Another graduate student played the role of a simulated nurse to assist the students with medication administration and test orders. We had results for the imaging and lab tests expected to be ordered according to each case, which would be available for students to view as requested. As the simulation scenario was the emergency room, a vital signs monitor was used for students to visualize heart rate, EKG, blood pressure, respiratory rate, oxygen saturation, and temperature throughout the simulation.

Students received a briefing about simulation and their tasks and how the nurse would assist them. They were all familiar with the videoconference meeting functions (individual and multiple-user screen sharing, visualization from multiple participants, and entering and leaving breakout rooms). Students were divided into groups of 4-5 members and entered the simulation in a videoconference meeting. There, they would find the simulated patient and nurse. Every participant was instructed to maintain open their video and microphone. They could use the chat function for sharing ideas among themselves. Upon request from student teams, the nurse would administer medications or take blood samples. Then she would show the results using the screen sharing function. During the simulation, the tutor would observe the students' performance and interaction, with the camera off and did not participate; but took notes of the students' decisions, actions, etc. After the 10-minute-long simulation, they would enter a breakout room for good-judgment debriefing with the tutor; for additional 10 minutes.

Students interacted with the simulated patient in an interview and asked for information about physical findings from the simulated nurse. According to the team's performance, the simulation adapted with variations in vital signs in the monitor and the patient's symptoms. They were provided with test results upon request. During the simulation, the patient would inquire about his disease, etiology, pathophysiology, clinical manifestations, complications, prognosis when the team members did not volunteer this information. 
Following the simulation, students received a good-judgment debriefing, addressing the motivations for their actions and verbalization during the simulation, looking for deep reflection in the student's performance and self-awareness of skills, knowledge, and attitudes. The students put into words the mental processes leading to decision-making. According to the notes taken during the simulation, the tutor guided the debriefing session, addressing the learning objectives for the course and activity. The tutor also reassured students' confidence and provided advice accordingly in strong and weak areas, providing reference articles, clinical examples, and personal experiences. Driven by the students' responses, the debriefing facilitated an insight into the mental models that drove the actions and discussion during the simulation, allowing students to enter a deep metacognition process.

The objective of this study was to assess the adaptation of the face-to-face clinical simulation to a virtual format to continue medical students' training in a social distancing context.

\section{Methods}

This study follows a quantitative descriptive and cross-sectional design. The sample consisted of 33 third-year medical students in a private university enrolled in the endocrine pathophysiology course during the fall semester 2020, between 19 and 21 years old. They were invited to participate voluntarily and signed informed consent before participating in the study. There were 25 female and 9 male participants.

The face-to-face simulation included a high-fidelity mannequin with vital signs monitoring and an active interview with a tutor as the patient's voice. According to the simulation scenario, the mannequin was disguised with makeup, edema, sores, or rashes. As students palpated the mannequin, the tutor would provide important information regarding pain or shortness of breath.

Since this required close contact in a closed setting, the educational strategy was redesigned to a remote format. In this case, adaptation consisted of introducing a virtual platform for interaction by a live video conference. We introduced 2 active role players: a simulated patient and a simulated nurse. For each, a script was written. In this scenario, the respective graduate students played the simulated patient's and nurse's roles. The script was practiced beforehand with each. The vital signs monitor was presented in the screen-sharing function in the video conference, with the aid of the Sim Lab technician. Lab tests and imaging studies were provided as requested by the student teams by the simulated nurse through the screen sharing function. The simulated patient would impersonate the role according to the endocrine disease. The simulated nurse provided the physical exam changes, as these were included in her script, since the participants could not perform the physical exam directly on the patient/mannequin, as in face-to-face.

Students were divided into 4-5 member teams and received an introductory briefing before the simulation. Each simulation lasted 10 minutes, followed by a 10-minute debriefing session. Debriefing sessions were held in small rooms in the videoconference platform. After this, the teams' performance in the simulation was assessed considering the scoring rubric of table 1, which uses a 10point Likert scale. 3 tutors assessed the teams in each simulation. The scores for each team integrated all the tutors' marks for each. 
Table 1: Team Performance Evaluation

\begin{tabular}{ll}
\hline Category & Description \\
\hline History of Present Illness & $\begin{array}{l}\text { Thorough interview of signs and symptoms; which includes all of } \\
\text { the following: time of evolution; associated symptoms; } \\
\text { exacerbating and mitigating factors, location, quality, severity, } \\
\text { timing, context, modifying factors, }\end{array}$ \\
\hline Main Problems Identified & Identifies the main problems in the clinical case. \\
\hline Appropriate Tests & Orders the adequate tests related to the disease. \\
\hline Appropriate Diagnoses & $\begin{array}{l}\text { Identifies the precise diagnosis, and differential diagnoses are } \\
\text { listed. }\end{array}$ \\
\hline Appropriate Therapy & Describes medication and therapy that is adequate for the illness. \\
\hline
\end{tabular}

All participants signed a confidentiality agreement related to all that occurred, was said, and done during the simulation. Students were required to have internet connectivity and the use of an electronic device, such as laptop, mobile or tablet which would allow them to connect to the videoconference, for the virtual simulation.

\section{Results}

According to the results, the team's performance was the highest in the identification of the main complaint that made the patient reach for help, and the description of the mechanisms of the disease with a mean of 8.50 and 8.33 , respectively. The lowest performance was found in the etiology and the definition of appropriate therapy, with a mean of 5.79 and 5.67, respectively (Table 2).

Table 2: Teams' Performance Assessment

\begin{tabular}{ll}
\hline Category & Mean Score \\
\hline History of Present Illness & \\
\hline Etiology & 5.79 \\
\hline Risk Factors & 6.00 \\
\hline$\quad$ Mechanisms of Disease & 8.33 \\
\hline Main Problems Identified & \\
\hline$\quad$ Chief Complaint & 8.50 \\
\hline$\quad$ Clinical Manifestations & 6.86 \\
\hline Appropriate Tests & 6.21 \\
\hline Appropriate Diagnosis & 6.25 \\
\hline Appropriate Therapy & 5.67 \\
\hline
\end{tabular}

By linear regression, there is the following correlation between the variables and the mechanism of disease. The highest correlation to the mechanism of disease was seen with Appropriate Diagnosis, and the least, with Appropriate Therapy (table 3). 
Table 3: Linear Regression Analysis

$$
\text { Correlation Coefficient Standard Error }
$$

\begin{tabular}{lll}
\hline Chief Complaint & 0.353 & 0.220 \\
Risk Factors & 0.568 & 0.232 \\
\hline Etiology & 0.339 & 0.493 \\
Clinical Manifestations & 0.446 & 0.224 \\
\hline Appropriate Tests & 0.243 & 0.178 \\
Appropriate Diagnosis & 0.787 & 0.209 \\
\hline Appropriate Therapy & 0.094 & 0.250 \\
\hline
\end{tabular}

According to the tutors' feedback, the factors present in all teams were introducing themselves and making questions related to the chief complaint. Only one team asked for allergies during the simulation, although all of the prescribed medication. This was an essential issue in debriefing since all students recognized this information is highly relevant in every case and should not be forgotten regardless of the clinical situation.

During the debriefing session, all teams agreed that the simulation was challenging and engaging. $80 \%$ of the teams agreed they had no organization in teamwork but are aware they need to next time; the remainder $20 \%$ agreed their teamwork could improve. Regarding pathophysiology explanation for the scenario, 65\%, 20\%, and 15\% performed high, regular, and low. Students' most common emotional factors were nervousness during the simulation, although they knew this was not part of a mark for their grade in the course. They agreed that being observed during the simulation is one factor that continuously distracted them from the clinical situation. Also, they were not familiar with this type of learning strategy but looking back at it; they think it is beneficial.

\section{Discussion}

As pointed out by some authors, simulation is now a cornerstone for medical training (Pottle, 2019). Adapting educational strategies using technology in remote teaching was essential for medical schools to continue their training amid COVID-19. Virtual simulation proved to help guarantee a safe learning environment to students and faculty during the present situation while providing a fresh look by introducing interaction through a videoconference platform. This is parallel to the studies conducted by Keiser and Restrepo, which proved that virtual simulation experiences provide engaging and interactive learning experiences (Isaza-Restrepo et al., 2018; Keiser \& Turkelson, 2018).

According to the results obtained, the teams were least able to identify the appropriate treatment and more able to identify the appropriate diagnosis of disease mechanisms. We think this is related to the nature of the course since it is a pathophysiology course in which students focus on the mechanisms underlying the pathological processes. They have not had clinical experience with medication prescription, explaining the low score in this criterion. The use of virtual simulation scenarios provides an engaging format for continuing these activities during the lockdown. The use of an assessment instrument aids in identifying strengths in the students' performance, and the debriefing 
session, even in small rooms in the virtual format, serves as an easy way to provide feedback to each team. The study of Al-Elq (2020) showed that debriefing is one of the most critical elements in simulation and supports learners' reflection and pointing out the lessons learned (So et al., n.d.). In this study, we did not focused on the distinction between skills according to those centered in patients, processes, and environment, as mentioned by Lane et al. (2001). This could be addressed in future research according to the types of skills in each category for the proposed scenarios.

The use of small rooms for debriefing provided a safe and private atmosphere for students to express themselves without the fear of being exposed or judged by others, as the confidentiality agreement also contributed to this purpose. Also, it encouraged peer trust for building an environment in which students would participate actively. This curricular adaptation exemplifies a proficient way to carry out virtual simulation activities amid the pandemic, which could be easily adapted to other disciplines and educational levels.

One limitation of this study was the small sample included, which relates to it being a pilot study. We think there is value as it provides information about the changes that should be included to expand the number of students participating in this activity. Faculty workload has increased dramatically during the pandemic, which also limited the number of teachers involved. Including more teachers from different fields within the health would provide an integrated comprehension of patient care, and integrating professionals from different fields may enrich the experience for students to understand the complexity of professional practice.

This adaptation in the format can be transferred to other courses, according to the contents. Also, this is transferable to other health sciences programs, as long as the scripts are appropriately adjusted. Special attention to the student's level of expertise is essential to obtain the best results. Also, maintaining small teams allows students to participate more actively, as compared with larger groups. We think that repeating the exercise in the same students can show better results as they become familiar with the simulations, which could contribute to increased confidence in themselves.

\section{Conclusion}

Virtual simulation adaptation contributes effectively to clinical training. The adaptation should relate to the level of the learner and the objectives in the course. Also, small groups make it possible to participate actively and feel the need to contribute to the case presented. The debriefing session stimulated students' self-awareness and critical thinking reflectively in an environment of respect and attentive listening, contributing to soft skills essential for healthcare workers. Other schools and professions can learn from this experience to foster targeted simulations of professional practice skills, in which students can practice and received timely feedback that supports their development.

The time availability is a significant limitation for the implementation. Students participated during their scheduled class time to avoid absences or interrupt other high-stake activities, such as evaluations or presentations, in those who accepted participating. Therefore, regular classwork was organized to permit the introduction of this activity. Other groups took more time to go through the course contents; still, there was no comparison between exams or other assessment methods for students participating in this study. This could be addressed in future implementations. Also, being a small sample of students participating in the study, further studies in this topic would benefit from an enlarged population to compare the results in a larger population. 
The pandemic seriously disrupted the inertia that some programs had on using highly traditional approaches for learning, and organizational learning must include incorporating these innovative solutions into the operation of new normality for students' training.

\section{References}

Ahmed, H., Allaf, M., \& Elghazaly, H. (2020). COVID-19 and medical education. In The Lancet Infectious Diseases (Vol. 20, Issue 7, pp. 777-778). Lancet Publishing Group. https://doi.org/10.1016/S1473-3099(20)30226-7

Al-Elq, A. H. (2010). Simulation-based medical teaching and learning. Journal of Family \& Community Medicine, 17(1), 35-40. https://doi.org/10.4103/1319-1683.68787

Brouwers, M., Custers, J., Bazelmans, E., Van Weel, C., Laan, R., \& Van Weel-Baumgarten, E. (2019). Assessment of medical students' integrated clinical communication skills: Development of a tailor-made assessment tool. BMC Medical Education, 19(1), 1-10. https://doi.org/10.1186/s12909019-1557-3

Buja, L. M. (2019). Medical education today: All that glitters is not gold. In BMC Medical Education (Vol. 19, Issue 1, pp. 1-11). BioMed Central Ltd. https://doi.org/10.1186/s12909-019-1535-9

Chick, R. C., Clifton, G. T., Peace, K. M., Propper, B. W., Hale, D. F., Alseidi, A. A., \& Vreeland, T. J. (2020). Using Technology to Maintain the Education of Residents During the COVID-19 Pandemic. Journal of Surgical Education, 77(4), 729-732. https://doi.org/10.1016/j.jsurg.2020.03.018

Culpa-Bondal, A., \& Dean, C. (2018). Increasing Students' Self-Confidence in Patient Interaction through Standardized Patient Simulations. Georgia College and State University, 2-29. http://hdl.handle.net/10755/601694

Friedman, C. P., Donaldson, K. M., \& Vantsevich, A. V. (2016). Educating medical students in the era of ubiquitous information. Medical Teacher, 38(5), 504-509. https://doi.org/10.3109/0142159X.2016.1150990

Isaza-Restrepo, A., Gómez, M. T., Cifuentes, G., \& Argüello, A. (2018). The virtual patient as a learning tool: A mixed quantitative qualitative study. BMC Medical Education, 18(1), 1-10. https://doi.org/10.1186/s12909-018-1395-8

Joseph, J. P., Joseph, A. O., Conn, G., Ahsan, E., Jackson, R., \& Kinnear, J. (2020). COVID-19 Pandemic-Medical Education Adaptations: the Power of Students, Staff and Technology. Medical Science Educator, 30(4), 1355-1356. https://doi.org/10.1007/s40670-020-01038-4

Keiser, M., \& Turkelson, C. (2018). Opportunities and Advantages With Virtual Technology Integration. In Virtual Simulation in Nursing Education. Springer Publishing Company. https://doi.org/10.1891/9780826169648.0005

Khan, K. Z., Ramachandran, S., Gaunt, K., \& Pushkar, P. (2013). The Objective Structured Clinical Examination (OSCE): AMEE Guide No. 81. Part I: An historical and theoretical perspective. 2(35), 1437-1446. https://doi.org/10.3109/0142159X.2013.818634

Laidlaw, A., Aiton, J., Struthers, J., \& Guild, S. (2012). Developing research skills in medical students: AMEE Guide No. 69. In Medical Teacher (Vol. 34, Issue 9, pp. 754-771). https://doi.org/10.3109/0142159X.2012.704438

Lane, J. L., Slavin, S., \& Ziv, A. (2001). Simulation in Medical Education: A Review. Simulation \& Gaming, 32(3), 297-314. https://doi.org/10.1177/104687810103200302

Maestre, J. M., \& Rudolph, J. W. (2015a). Teorías y estilos de debriefing: el método con buen juicio como herramienta de evaluación formativa en salud. Revista Española de Cardiología, 68(4), 282285. https://doi.org/10.1016/j.recesp.2014.05.018 
Maestre, J. M., \& Rudolph, J. W. (2015b). Theories and Styles of Debriefing: the Good Judgment Method as a Tool for Formative Assessment in Healthcare. Revista Española de Cardiología (English Edition), 68(4), 282-285. https://doi.org/10.1016/j.rec.2014.05.018

Olivares Olivares, S. L., \& Valdez-García, J. E. (2017). Aprendizaje Centrado en el Paciente. In Editorial Médica Panamericana. Editorial Médica Panamericana.

Patel, S. M., Miller, C. R., Schiavi, A., Toy, S., \& Schwengel, D. A. (2020). The sim must go on: adapting resident education to the COVID-19 pandemic using telesimulation. Advances in Simulation, 5(1), 26. https://doi.org/10.1186/s41077-020-00146-w

Pottle, J. (2019). Virtual reality and the transformation of medical education. Future Healthcare Journal, 6(3), 181-185. https://doi.org/10.7861/fhj.2019-0036

Regehr, G. (2004). Trends in Medical Education Research. Academic Medicine, 79(10), 939-947. https://journals.lww.com/academicmedicine

Segura-Azuara, N. de los Á., Eraña-Rojas, I. E., \& López-Cabrera, M. V. (2018). High-fidelity simulation in pathophysiology courses with medical students. Educación Médica, 19(6), 355-358. https://doi.org/10.1016/j.edumed.2017.12.003

So, H. Y., Chen, P. P., Kwok, G., Wong, C., Tung, T., \& Chan, N. (n.d.). Simulation in medical education. https://doi.org/10.4997/JRCPE.2019.112

Tabatabai, S. (2020). Simulations and virtual learning supporting clinical education during the covid 19 pandemic. In Advances in Medical Education and Practice (Vol. 11, pp. 513-516). Dove Medical Press Ltd. https://doi.org/10.2147/AMEP.S257750

Torres, A., Domańska-Glonek, E., Dzikowski, W., Korulczyk, J., \& Torres, K. (2020). Transition to online is possible: Solution for simulation-based teaching during the COVID-19 pandemic. Medical Education, 54(9), 858-859. https://doi.org/10.1111/medu.14245

Turner, T. L., Palazzi, D. L., \& Ward, M. A. (2010). The Clinician-Educator's Handbook (MedEdPortal (ed.)). MedEdPortal. https://doi.org/https://doi.org/10.15766/mep_2374-8265.7749

Valdez-García, J. E., López Cabrera, M. V., Jiménez Martínez, M. de los Á., Díaz Elizondo, J. A., Dávila Rivas, J. A. G., \& Olivares Olivares, S. L. (2020). Me preparo para ayudar: respuesta de escuelas de medicina y ciencias de la salud ante COVID-19. Inv Ed Med, 9(35), 9-11. https://doi.org/10.22201/facmed.20075057e.2020.35.20230

Wang, J., \& Shi, X. (2020). Harmonizing the COVID-19 Pandemic Response with Economic and Social Recovery. China CDC Weekly, 2(36), 704-707. https://doi.org/10.46234/ccdcw2020.171 